\title{
Propuesta para un redimensionamiento del denominado derecho general de la personalidad
}

Juan Espinoza Espinoza

\section{Premisa}

La tutela de los derechos de la persona ha sido una preocupación constante (aunque oscilante) de toda cultura jurídica. Ello se ha acentuado notoriamente después de la Primera Guerra Mundial. En efecto, si hacemos una mirada retrospectiva, constatamos que el jurista decimonónico regularizaba pormenorizadamente los derechos patrimoniales, dejando de lado aquellos denominados (debido a la carga ideológica imperante) extra-patrimoniales, por cuanto se pensaba que formaban parte del derecho natural y no requerían una tutela específica por parte del derecho positivo. Incluso, cuando comenzó a teorizarse sobre los derechos de la persona, se pretendía -erróneamente- explicar los mismos a través de esquemas propios de los derechos patrimoniales, principalmente, el derecho subjetivo de la propiedad. Es a partir de los aportes de la filosofía existencialista y de la corriente del personalismo ético que el jurista contemporáneo se sensibiliza y comienza a producir modelos jurídicos que se basan en la tutela de la persona, entendida como eje y centro del ordenamiento jurídico ${ }^{1}$. Sin embargo, cada sistema jurídico ha asumido criterios propios en lo que se refiere al reconocimiento de los derechos de la persona y en los mecanismos de tutela de los mismos.

1 Así, Fernández Sessarego, Un nuovo modo di fare diritto, en Il diritto dei nuovi mondi, a cura de Visintini, CEDAM, Padova, 1994, p. 238. 
Así tenemos que en Alemania se reconoce un derecho general de la personalidad (allgemeines Persönlichkeitsrecht), el cual está dirigido a la conservación, inviolabilidad, dignidad y libre desenvolvimiento del individuo. Y en el common law norteamericano insurge el right of privacy, entendido como síntesis de las situaciones jurídicas existenciales de las personas (no como equivocadamente se piensa: sinónimo del derecho a la privacidad). De estos derechos generales (o "madres»), surgen otros derechos especiales (o «hijos»).

Los ordenamientos jurídicos que no han adoptado el modelo de un derecho general de la personalidad, reconocen legislativamente un elenco limitado de derechos de la persona: es el caso de todos los sistemas del civil law que siguen el modelo diseñado por el código civil francés.

Esta diferenciación que, producto de un enjuiciamiento apresurado, podría parecer de corte académico, resulta de suma incidencia práctica frente a la adopción de técnicas de tutela frente a posibles abusos que se puedan presentar. En efecto, si tomamos como ejemplo el tema de los abusos de la informática, ante una posible legislación que tenga como objetivo limitar los mismos, se presentan dos posibilidades: si estamos en un sistema como el francés: es imperativo individualizar qué derechos serían los que desea proteger (sea intimidad, identidad, reputación, entre otros), asumiendo la contingencia que pueda quedar desprotegido alguno (imagen o voz, por ejemplo). En cambio, si nos encontramos frente a un sistema como el alemán o el estadounidense, el derecho general de la personalidad, o el right of privacy, tutelaría cualquier derecho (o situación jurídica de ventaja) de la persona. Estas situaciones las vemos reflejadas, de alguna manera, en la ley federal de Alemania de 1977, en materia de Datenschutz, en el Privacy Act de Estados Unidos de Norteamérica de 1974 y en la Loi relative à l'informatique, aux fichiers et aux libertés francesa de 1978.

\section{II.El derecho general de la personalidad (allgemeines} Persönlichkeitsretch) de la experiencia alemana frente al derecho a la información

Se ha afirmado con razón que en el derecho alemán, el tema de la tutela civil de los derechos de la persona, si bien es cierto, es objeto de una producción jurisprudencial no siempre coherente, la cual ha generado un debate doctrinario riquísimo, ha sido unánime que en estas 
últimas cuatro décadas la jurisprudencia no ha reconocido derechos individuales de la personalidad, sino aspectos especiales (o singulares) de un derecho general, cuyo objeto es la persona humana, entendida en sus «innumerables e incatalogables manifestaciones». ${ }^{2}$ Es así que, los intérpretes de la Constitución de Bonn identifican, en los artículos $1^{0^{3}}$ y $2^{0^{4}}$ del Grundgesetz, la fuente directa del derecho general de la personalidad, fundado en la inalienable pretensión del hombre del respeto de la propia dignidad y el libre desarrollo de la propia personalidad. ${ }^{5}$

Esta posición subjetiva se configura, en primer lugar como un Grundrecht, constitucionalmente protegido frente a cualquier autoridad pública y al mismo tiempo como un derecho subjetivo privado que cada uno puede hacer valer frente a comportamientos lesivos del mismo, realizados por cualquier otro sujeto. ${ }^{6}$

En lo que se refiere a la tutela frente a los conflictos entre el derecho general de la personalidad y el derecho de (y a) la información, el Tribunal Constitucional Federal (Bundesverfassungsgeritch), cuenta con una decisión, de fecha 16.07.69 (denominada Mikrozensusentscheidung), la cual se refería a la legitimidad constitucional de una revelación estadística de muestreo, que tenía como objeto los viajes de descanso y vacaciones realizados por los ciudadanos alemanes. Frente a la cuestión de la posible lesión -ocasionada por dicha investigación- del Grundrecht,

2 Así Somma, en Corso di Sistemi Giuridici Comparati, a cura de alpa, Giappichelli, Torino, 1996, 395.

3 Art. $1^{\circ}$ "(1) La dignidad del hombre es intangible. Respetarla y protegerla es obligación de todo poder político.

(2) El pueblo alemán se identifica, por lo tanto, con los inviolables e inalienables derechos del hombre como fundamento de toda comunidad humana, de la paz y de la justicia en el mundo.

(3) Los siguientes derechos fundamentales vinculan a los poderes legislativo, ejecutivo y judicial a título de derecho directamente aplicable".

Este último inciso fue reformado por Ley federal del 19.03 .56 (la versión en español y los datos han sido tomados de Pina, Cláusulas constitucionales operativas y programáticas. Ley Fundamental de la Repuiblica Federal de Alemania, Astrea, Buenos Aires, 1973, p.116).

4 Art. $2^{\circ}$ "(1) Todos tienen derecho al libre desenvolvimiento de su personalidad siempre que no vulneren los derechos de otro ni atenten al orden constitucional o a la ley moral. (2) Todos tienen derecho a la vida y a la integridad física.

La libertad de la persona es inviolable. Estos derechos sólo podrán ser coartados en virtud de una ley" (Pina, op. cit., pp.116-117)

5 Roppo, I diritti della personalità, en Banche dati telematica e diritti della persona, a cura de Alpa y Bessone, CEDAM, Padova, 1984, p. 73.

6 Roppo, op. cit. 
codificado en los artículos $1^{\circ}$ y $2^{\circ}$ de la Constitución, entendida en el sentido que el libre y autónomo desarrollo de la persona del individuo, se concreta en un Innenraun "en el cual éste puede retirarse, al cual el ambiente externo no tiene acceso, dentro del cual éste es dejado en paz y goza de un derecho a la soledad", ${ }^{7}$ el Bundesverfassungsgeritch observa que, sin embargo, delante de las exigencias de las modernas organizaciones sociales y estatales, este derecho no puede considerarse ilimitado. La Corte concluye que en este caso, debido a la garantía del anonimato y al hecho de que el cuestionario no invadía el innerste Intimbereich de los entrevistados, no se veía contraste con el derecho general de la personalidad, constitucionalmente protegido.

Otro caso, de fecha 15.01.70, siempre referente a la declaración de inconstitucionalidad, se refiere al hecho de que si en la evaluación de un procedimiento disciplinario de un funcionario público, fuese legítima la utilización de documentos de su proceso de divorcio, sin el consentimiento previo del ex-cónyuge. Los jueces, partiendo de las consideraciones que la tutela de los derechos de la persona no es ilimitada ni incondicional, que el criterio a utilizar para evaluar si en el caso concreto la intrusión sea ilícita es que la misma sea justificada «en el prevaleciente interés de la colectividad, a la luz de un estricto cumplimiento del requisito de la proporcionalidad ${ }^{8}$ (Verhaltnismässigkeitsangebot), se llegó a la conclusión que dicho procedimiento fue ilícito.

Un tercer caso, que se falló con sentencia de fecha 08.03.72, se produjo cuando, en el curso de un proceso penal se incautó, en un estudio médico, la historia clínica del imputado. El Bundesverfassungsgeritch repitió fielmente las tres proposiciones de reconocimiento, en vía de principio, del derecho constitucional al respeto de la esfera íntima (Intimaphäre del Einzelnen); del carácter relativo, no absoluto, de la tutela y del recurso al criterio del interés público y de la proporcionalidad entre éste y la gravedad de la lesión. Se llegó a la conclusión de que este hecho constituía la violación del Grundretch del paciente al respeto de su vida privada (seines private Bereichs), aun en el caso de que la historia clínica no esté en posesión del médico tratante pero se encuentre en custodia de un colega que ha revelado la misma. ${ }^{9}$

\footnotetext{
7 Roppo, op. cit., pp. 74-75.

8 Roppo, op. cit., pp. 75-76.

9 Roppo, op. cit., p. 76.
} 
Particular atención merece la sentencia de fecha 05.06.73. Ciertos media se encargaron de difundir, a través de reportajes y entrevistas, un hecho sangriento ocurrido en el pasado, generando la reacción del autor del delito (que no era un personaje público), el cual lamentaba la violación de la propia esfera de la personalidad. Ante el manifiesto conflicto entre el principio de libertad de radiodifusión (Rundfunkfreiheit) (consagrado en el Art. $5^{010}$ de la Constitución federal alemana) y el principio de la protección de la persona (Persönlichkeitschutz) (regulado en el Art. $2^{\circ}$ ), los jueces observaron que ninguno de los dos principios puede pretender, en vía general, una superioridad sobre el otro, siendo necesario realizar una detenida evaluación de intereses (Interessenabwägung), evaluando la magnitud -según sea el caso- del interés a la información de la colectividad. En el caso particular de los reportajes sobre graves hechos criminales, el interés a la información de la colectividad prevalece, en línea de máxima, sobre el interés a la tutela de la personalidad del reo. Sin embargo, también en esta materia debe hacerse una concreta aplicación del criterio de proporcionalidad, bajo el cual no puede considerarse admisible una específica identificación del autor del delito, se entiende, en los reportajes de actualidad. Para el caso de los reportajes difundidos después de un cierto tiempo, posterior al suceso, el criterio es mucho más rígido: estos son considerados inadmisibles cuando generen el riesgo de ocasionar un perjuicio nuevo y adicional, particularmente, si ponen en peligro las perspectivas de una reinserción en la sociedad (con la precisión que tal peligro debe presumirse por regla, si la transmisión relativa a un hecho criminal antiguo, que identifique a los ojos del público al autor, sea difundida después de su excarcelación o poco antes de ésta) ${ }^{11}$.

En 1977, el Bundesverfassungsgeritch, evaluó la constitucionalidad de un procedimiento de incautación, en una organización de asistencia

10 Art. $5^{\circ}$ "(1) Todos tienen el derecho de expresar y difundir libremente su opinión por medio de la palabra, por escrito y por la imagen, y de informarse sin trabas en las fuentes accesibles a todos. La libertad de prensa y la libertad de información por radio y cinematografía están garantizadas. No se ejercerá censura.

(2) Estos derechos tienen su límite en las disposiciones de las leyes generales, las medidas legales adoptadas para prorección de la juventud y el derecho del honor personal.

(3) El arte, la ciencia, la investigación y la enseñanza son libres. La libertad de enseñanza no exime de la fidelidad a la Constitución" (Pina, op. cit., pp. 117-118).

11 Roppo, op. cit., pp.76-77. 
de toxicómanos, de datos relativos a los usuarios de la misma: se trataba de determinar si estaba en contraste con la garantía constitucional del allgemeines Persönlichkeitsrecht, bajo la doble perspectiva de una posible lesión de la libertad de acción (Handlungsfreibeit) del titular de la organización y del Grundretch de los usuarios respecto de su propia esfera personal. Repitiendo una distinción utilizada no pocas veces, la Corte observa que los documentos incautados no comprometen la inviolabilidad de la intimidad personal (Unantatbare Intimsphäre); pero sí afectan el ámbito privado (privaten Bereich) de los usuarios. La tutela de éstos no se configura de manera absoluta, sino relativa y es medida sobre la base del socorrido criterio de la proporcionalidad: el procedimiento es declarado ilegítimo si la lesión que se originaría en la esfera privada (también desde el aspecto de un eventual perjuicio a la terapia en curso) es desproporcionadamente grave respecto de los objetivos perseguidos con el secuestro y se precisa que tal desproporción es in re ipsa cuando la incautación se funde en la genérica sospecha que los usuarios sean imputables de adquisición y tenencia ilegal de estupefacientes. $^{12}$

Finalmente, se señala una interesante aplicación del allgemeines Persönlichkeitsrecht, hecha por un juez administrativo, con fecha 03.09.70. Una trabajadora había solicitado, sobre la base de la normatividad relativa a la seguridad social, el reembolso de los gastos del parto realizados por un embarazo fuera del matrimonio. Frente al rechazo del ente erogador, motivado por la observación que la pretensión del reembolso se hubiera podido hacer valer ante el padre natural, la trabajadora lo impugna. El Bundesverfassungsgeritch le da la razón, basándose en el derecho constitucional de la mujer respecto de su Intimsphäre, fundado a su vez, en el Grundretch al libre desarrollo de la personalidad. ${ }^{13}$

12 Roppo, op. cit., p.78.

13 Los jueces motivaron que tal derecho "vale ciertamente también en las relaciones entre dependientes y empleador y cubriendo, sin lugat a dudas, las decisiones autónomas del sujeto en orden a sus relaciones extramatrimoniales que tengan como consecuencia el nacimiento de un hijo natural, cubre además la decisión de la mujer de revelar, o no, la identidad del padre, $y$ de hacer valer, o no, en contra de éste, pretensiones patrimoniales vinculadas con el embarazo y el parto" (Roppo, op. cit., p. 79). 


\section{El right of privacy del common law norteamericano}

En lo que se refiere a este derecho, resulta forzoso comenzar con la historia de un joven abogado que se había casado con la hija de un senador y que había comenzado a tener una vida particularmente lujosa y dispendiosa. El escenario: Boston, el año: 1881. Este hecho comenzó a llamar la curiosidad y generó comentarios en los periódicos en sus crónicas mundanas, hasta llegar a ocasionar un escándalo. Este abogado, llamado Samuel D. Warren, irritado con la invasión a su vida privada, se asoció con un antiguo compañero de estudios de la Universidad de Harvard, Louis D. Brandeis, quien después sería juez de la Corte Suprema de los Estados Unidos, y conjuntamente escribieron un ensayo, titulado The right to privacy, que fue publicado en la Harvard Law Review. Según estos dos autores, todo individuo tiene el derecho to be let alone, de ser dejado en paz, de proteger su soledad, es decir su vida íntima, tanto como tiene el derecho de proteger su vida privada ${ }^{14}$.

Se afirma, con razón que "las discusiones teóricas y las complejas experiencias de estos años muestran que la privacy se presenta ahora como una noción fuertemente dinámica y que se ha establecido una estrecha y constante interrelación entre los cambios determinados por las tecnologías de la información (pero también por las tecnologías de la reproducción, de la ingenería genética) y los cambios del mismo concepto. Una definición de la privacy como "derecho a ser dejado solo", como simple reserva, desde hace tiempo ha perdido un significado general, aunque si individualiza un valor, asume un aspecto esencial del problema y puede ser aplicada a situaciones específicasm. ${ }^{15}$

El right of privacy ha evolucionado tanto desde su reconocimiento jurisprudencial que ha desbordado su concepción inicial. Es por ello que se sostiene que una traducción del mismo en términos de «derecho general de la personalidad" sería más apropiada que una traducción gramatical de simple «derecho a la reserva», palabras "que sonarían verdaderamente reductivas frente a la intensidad y a la riqueza semántica contenida en la fórmula de la privacy ${ }^{16}{ }^{16}$ Resulta sumamente inte-

14 Frosini, Diritto alla riservatezza e calcolatori elettronici, en Banche dati telematica e dirirri della persona, op. cit., p.29.

15 Rodotà, Repertorio di fine secolo, Sagitari Laterza, Roma-Bari, 1992, p.189.

16 Roppo, op. cit., p.62. En esta mismo sentido, se afirma que «la propuesta de mantener 
resante observar el proceso (y los cambios dentro del mismo) por el cual ha pasado este derecho.

El derecho a la privacy no encuentra una mención expresa, ni una tutela específica en ningún artículo de la Constitución norteamericana y, sin embargo, éste expresa valores constitucionales. Su tutela constitucional se ha afirmado a través de numerosas decisiones de la Corte Suprema. Dentro del right of privacy conviene distinguir la privacy of disclosure $^{17}$ de la privacy of autonomy ${ }^{18}$.

\subsection{Tutela de la privacy of disclosure}

Las decisiones que se refieren a la disclosural privacy, se basan en la cuarta enmienda de la Constitución ${ }^{19}$, que es la que más se aproxima a regular esta situación, a falta de una disposición expresa. Un caso de antigua data (1886) es Boyd vs. United States, en el cual se concluye con una declaración de inconstitucionalidad de una ley que consentía que en los procesos en material fiscal, el juez pudiese imponer al demandado exhibir en el proceso libros contables, así como otros documentos privados y en el caso de falta de cumplimiento, se preveía que las informaciones o alegatos, recogidos en contra del sujeto, deberían con-

inalterado el vocablo de "privacy", sin intentar una traducción mecánica, parece ser la más adecuada", por cuanto los lemas equivalentes en otro idioma "no describen sino aspectos singulares, circunscritos y no revelan la complejidad de las situaciones en referencia" (Alpa, Privacy e statuto dell'informazione, en Banche dati telamatica e diritti della persona, ob. cit., p. 201). Asimismo, el autor, citando a Prosser, afirma que las figuras de privacy que se han delineado son esencialmente cuatro (op. cit., pp.235-236):

1. La intrusión en la soledad o en el apartamiento del individuo (es el denominado «derecho a ser dejado solon).

2. La revelación al público de hechos embarazosos.

3. La lesión de la reputación del individuo o su representación bajo una falsa luz.

4. La apropiación y el uso del nombre con fines lucrativos.

17 La cual es definida como «el derecho a controlar el flujo de información que se refiere a los detalles de la individualidad de cada uno" (Roppo, op. cit., p. 63).

18 Entendida como uel aspecto de la privacy concerniente a la habilidad individual de decidir realizar ciertos actos o asumir ciertas experiencias sin sufrir interferencias externas» (Roppo, ob. cit).

19 Que establece lo siguiente: «El derecho de los habitantes de que sus personas, domicilios, papeles y efectos se hallen a salvo de pesquisas y aprehensiones arbitrarias, será inviolable, y no se expedirán al efecto mandamientos que no se apoyen en un motivo verosímil, estén corroborados mediante juramento o protesta y describan con particularidad el lugar que deba ser registrado y las personas o cosas que han de ser detenidas o embargadas». 
siderarse probados. La declaración de inconstitucionalidad es fundada en un concepto amplio de privacy tutelada por la cuarta enmienda: un concepto tan amplio que es entendido de manera "desmaterializada", carente de referencias físicas. Se establece que la cuarta enmienda tutela la privacy del individuo, no sólo contra «la ruptura de sus puertas y el rebuscamiento de sus cajones", sino también contra "la invasión de su indefenso derecho a la seguridad personal, libertad personal y propiedad privadaw ${ }^{20}$

Esta posición sufre un viraje extremo en 1928, con la decisión del caso Olmatead vs. United States, donde la tutela (amparada en la cuarta enmienda) se restringe a proteger este derecho sólo frente a intromisiones de tipo material. Se trataba de juzgar la legitimidad de una interceptación telefónica dispuesta por la autoridad con la finalidad de prevenir una sospecha de tipo criminal. Con una reducida mayoría (cinco a cuatro), la Corte se decidió por la inexistencia de una violación inconstitucional del right of privacy protegido por la cuarta enmienda, por cuanto se entendió que este prohibe sólo formas de "actual physical invasion» de la habitación del ciudadano (que en el caso no se había verificado, puesto que el instrumento para la interceptación había sido colocado en cables externos a la casa), y además se refiere a la búsqueda de cosas tangibles (mientras que en esta ocasión la autoridad apuntaba a captar palabras expresadas oralmente, de ninguna manera asimilables a objetos materiales), llegando a considerar que la privacy fuese tutelable en los límites de un trespass en sentido técnico. ${ }^{21}$

Entre los jueces de minoría, el dissent más enérgico contra tal concepción (materialista y restrictiva) del ámbito de tutela de la privacy fue expresado por Brandeis, quien sostuvo lo siguiente: «los autores de nuestra Constitución buscaban proteger a los americanos en sus creencias, sus emociones y sus sensaciones" y para tal efecto "ellos confirieron, junto con el Gobierno, el derecho a ser dejado solo - el más comprensivo de los derechos y el derecho más valioso para los hombres civilizadosm. ${ }^{22}$

En 1967, con la decisión del caso Katz vs. United States, la Corte Suprema retorna a una concepción de privacy más «espiritualizada» $\mathrm{y}$,

20 Roppo, op. cit., p. 64.

21 Roppo, op. cit.

22 Roppo, op. cit., p. 65. 
por consiguiente, a una tutela más amplia. En este caso se excluye la admisibilidad de pruebas obtenidas interceptando y registrando una conversación telefónica efectuada desde una cabina pública. De manera explícita, se descarta la idea que el límite de la esfera individual protegida, a título de privacy, pueda identificarse dando trámite a una calificación de los espacios físicos en los cuales el individuo opera: los jueces observan que «la cuarta enmienda protege las personas, no los lugares». Mientras lo que uno concientemente expone al público, incluso en su casa o en su trabajo, «no cae bajo la tutela de la cuarta enmienda", contrariamente "lo que él tiende a mantener reservado, incluso en un espacio abierto al público, puede ser constitucionalmente protegido". Concretamente: la tutela de la privacy es autónoma de la tutela del domicilio, y está vinculada a la existencia de una inmaterial zone of privacy que es inherente a la persona, sea cual fuere el lugar donde ésta se encuentre. ${ }^{23}$

Este grupo de sentencias permite ver con mayor claridad que es imposible aprehender las situaciones jurídicas existenciales (privacy) a la luz de los criterios propios de las situaciones jurídicas patrimoniales (property). En efecto, cada una de ellas se desenvuelve en dos categorías distintas: la primera en la categoría del ser y la segunda en la categoría del tener. Cada una con sus propios principios e ideología ${ }^{24}$.

\subsection{Tutela de la privacy of autonomy}

Dentro del conjunto de casos que forman parte de la privacy of autonomy, se encuentra Griswold vs. Connecticut. En 1965, la Corte Suprema juzgó como inconstitucional (limitadamente a su aplicación con respecto a las parejas casadas) un statute que prohibía la prescripción y el uso de anticonceptivos. La razón de la inconstitucionalidad

23 Roppo, op. cit.

24 Así, con acierto se opina que: «En esta materia no se puede aplicar el derecho subjetivo elaborado sobre la categoría del tener. En la categoría del ser no existe la dualidad entre sujeto y objeto porque ambos representan el ser y la titularidad es institucional, orgánica. Donde el objeto de tutela es la persona, la perspectiva debe cambiar; se vuelve necesidad lógica reconocer, por la especial naturaleza del interés protegido, que es justamente la persona la que viene a constituir, al mismo tiempo, el sujeto titular del derecho y el punto de referencia objetivo de la relación" (Perlingieri, Il diritto civile nella legalità costituzionale, ESI, Napoli, 1991, p.323). 
fue identificada en la lesión que se ocasionaba al constitucional right of privacy, especificado en su particular acepción de marital privacy, vale decir, de libertad de autodeterminarse en los propios comportamientos familiares, sin interferencias o limitaciones por parte de la autoridad pública. ${ }^{25}$

Otro caso, Eisenstadt vs. Baird, relativo también a la libertad de usar anticonceptivos, se presentó en 1972. La novedad está en reconocer esta libertad también a personas no unidas en matrimonio. Se realiza una ampliación significativa en la esfera de la aplicación del right of privacy, a nivel de la denominada privacy of the bedroom, referida al individuo como tal y no sólo al individuo que forma parte de una relación conyugal formal. ${ }^{26}$

En 1973, se incorporó a esta familia de supuestos, la decisión de la Corte Suprema en el caso Roe vs. Wade, en el cual se declaró inconstitucional un statute que prohibía el aborto, salvo cuando había peligro de vida de la mujer (se trataba de una mujer no casada). La decisión se fundó en el reconocimiento de un «derecho absoluto» de la mujer de interrumpir el embarazo dentro del primer trimestre: un derecho en el cual la Corte no ve sino la especificación del general right of privacy. ${ }^{27}$

También en 1969 la Corte Suprema reconoció, en el caso Stanley vs. Georgia, el derecho de tener, en la propia casa, material obsceno, fundándose, en una parte, por la primera enmienda ${ }^{28}$ y en otra, por la existencia de un "derecho fundamental a ser libre, salvo en bien limitadas circunstancias, frente a indeseadas intrusiones del gobierno en la

25 Roppo, op. cit., p.69.

26 Roppo, op. cit., pp.69-70.

27 Roppo, op. cit., p.70. Sobre este caso, ya hablamos advertido que el abuso del ejercicio del derecho a la privacy, entendido en sentido lato, como un poder de autodeterminación sin ser armonizado con los intereses de los demás, amenaza con devenir, usando una feliz expresión de Beccaria, vuelta a proponer por Rodotà, en otro "terrible derecho", junto a la propiedad (Busnelli, Diritti unami e civiltà giuridica. Riflessione di un civilista, en Rass. Dir. Civ., 2, 1991, p.243). Dijimos que: «ocurre percibir el derecho en una dimensión de coexistencialidad, tratando de funcionalizar recíprocamente los intereses de las partes en conflicto y tutelando a las partes débiles, así dejaremos de visualizar unilateralmente la experiencia jurídica y la entendetemos de una manera más solidaria” (Espinoza Espinoza, Estudios de Derecho de las Personas, segunda edición, Huallaga, Lima, 1996, pp.139-140).

28 Que establece lo siguiente: «El Congreso no hará ley alguna por la que adopte una religión oficial del Estado o se prohiba practicarla libremente, o que coarte la libertad de palabra o de imprenta, o el derecho del pueblo para reunirse pacíficamente y para pedir al gobierno la reparación de agravios». 
privacy de uno". Sin embargo, en el caso Paris Adult Theatre I vs. Slaton, en el cual la Corte Suprema estudió el problema si el derecho a la privacy, cubría también la protección pública de las películas obscenas, sobre la base de lo decidido en el caso Stanley vs. Georgia, se asumió una actitud negativa, por cuanto la privacy of the home no puede equipararse, a nivel de intensidad de tutela, a una general zone of privacy que tenga el consumidor de material obsceno dondequiera se encuentre. ${ }^{29}$

Todos estos casos permiten llegar a la conclusión que la diferencia fundamental entre disclosural privacy y privacy of autonomy, es que en la primera, la Corte Suprema afirma una tutela amplia, que no está vinculada a la referencia de lugares físicos ni a la habitación del mismo, sino a la persona del individuo. Contrariamente, la privacy of autonomy, goza de una protección generalmente circunscrita a las actividades que el sujeto desenvuelve en su propia casa ${ }^{30}$, incluyendo dentro de las mismas, a las decisiones vitales del mismo (las cuales no se circunscriben a un ámbito geográfico determinado).

\section{Propuesta para un redimensionamiento del denominado Derecho General de la Personalidad}

La experiencia alemana del allgemeines Persönlichkeitsretch y norteamericana de la privacy, son ejemplos emblemáticos de aplicación legislativa, a nivel constitucional, de lo que en doctrina se llama teoría monista, en la cual (como ya lo advertimos anteriormente) se admite la existencia de un solo derecho general de la responsabilidad, del cual se desprenden derechos «hijos». La teoría atomista, en cambio, admite la existencia de una pluralidad de derechos de la persona. La percepción tradicional de asumir una u otra teoría, lleva consigo la consecuencia de admitir (o no) el reconocimiento que nuevas situaciones jurídicas existenciales ingresen a formar parte de la familia de los derechos de las personas. ${ }^{31}$

29 Roppo, op. cit.

30 Roppo, op. cit., p. 71.

31 Así, cuando se explica que: «la persona, en su relevancia sub specie iuris, es entendida en sentido atomista y pluralista, como resultado de toda una serie de derechos expresamente 
Desde mi punto de vista, el hecho de que se hable de un derecho o de varios derechos de la personalidad, nada tiene que ver con la tipificación de tales derechos y la consiguiente exclusión de otros: esta selección corresponde a un momento posterior, el cual es el de la técnica legislativa a optarse para regular los derechos de las personas. Parece más importante distinguir primero los niveles en los cuales se pueden entender los derechos de las personas, los que, como todo producto jurídico, tienen una dimensión normativa, valorativa y ontológica. ${ }^{32}$

En efecto, en el plano valorativo existe un solo fundamento de los derechos de las personas, que es la realización el proyecto vital de existencia de la persona, su realización como ser humano, entendido éste como un valor en si mismo. ${ }^{33}$ Este fundamento "único» no es más que el allgemeines Persönlichkeitsretch de los alemanes (que lo entienden a

reconocidos por el legislador a tutela de los intereses connaturales a la persona misma, pero específicamente individualizados; o en sentido global o unitario, como expresión de la acción de todo el conjunto de leyes positivas que tienen como finalidad la conservación y el desarrollo del sujeto, por una parte, y de las potencialidades intrínsecas de la persona emergentes en el ordenamiento y por otra. La diferencia entre los dos puntos de vista, sobre el plano práctico, es tal de poder conducir también a resultados del todo diversos e, incluso, opuestos: la tutela de un determinado interés de la persona que no corresponda a alguna de las tipificaciones normativas [...] es de excluirse o de incluirse en la categoría en la cual se engloba la tutela de la persona según que se adopten las teorías pluralistas o las unitarias. Estas últimas parecen, en el panorama cultural actual, prevalecer netamente" (Messinetti, Personalità (diritti della), en Enciclopedia del diritto, Giuffrè, 1983, p.356).

32 Así, se afirma que "la realidad jurídica es compleja. Existe una pluralidad de elementos que integran la ciencia jurídica. Y para captar adecuadamente lo "jurídico" se requiere no prescindir de ninguno de ellos. Los estratos ontológico, estimativo y lógico se exigen mutuamente en una unidad. En la unidad del Derecho. Podemos apreciar aisladamente la conducta como libertad, las normas como pensamiento y los valores como seres ideales objetivos con validez propia, pero para captar "lo jurídico" en su integridad debemos considerar aquellas categorías en su inescindible unidad" (Fernández Sessarego, El derecho como libertad. Preliminares para una filosofia del derecho, Studium, Lima, 1987, p.96).

33 Así, Rivera, cuando sostiene que: «Pese a que reconocemos distintas especies de derechos de la personalidad [...] debe puntualizarse con toda claridad que ellos reconocen un fundamento único, y que está dado, por el reconocimiento de que la personas tiene un valor en sí misma, y como tal cabe reconocerle una dignidad», Instituciones de Derecho Civil. Parte General, II, Abeledo-Perrot, Buenos Aires, 1993, p. 25). ). Sin embargo, esta posición no es unánime en doctrina, afirmándose que el objeto de los derechos de la persona lo constituyen «manifestaciones determinadas físicas o espirituales de la personas, objetivadas por el ordenamiento normativo y llevadas al rango de bienes jurídicos" (Cifuentes, Derechos personalísimos, $2^{\text {a }}$. edición actualizada y ampliada, Astrea, Buenos Aires, 1995, p.175). 
nivel normativo y no valorativo). ${ }^{34}$ en su contenido, el fundamento único y el derecho general de la personalidad alemán no son más que la misma cosa y si queremos ser más técnicos, diré que hay identidad conceptual en ambas figuras. En el plano normativo entiendo que no se puede hablar de un solo derecho de la persona sino de una plurali$\mathrm{dad}$, porque resulta obvio que todo ordenamiento jurídico reconoce (y va reconociendo) diversas situaciones jurídicas existenciales merecedoras de tutela jurídica. ${ }^{35}$

En lo que se refiere al aspecto de la técnica legislativa a utilizarse para la tutela de los derechos de la persona, independientemente de la posición que se asuma -vale decir-, uno o varios derechos resulta más conveniente aquella del numerus apertus. Por ello, coincidimos plenamente con quien sostiene que "No hay, en consecuencia, un número cerrado de derechos de la persona. Al lado de los derechos subjetivos perfectos, tipificados por el ordenamiento jurídico positivo, existen otros intereses de la persona que se erigen en derechos subjetivos imperfectos en la medida que, fundándose y derivándose de la propia dignidad de la persona humana, son también dignos de tutela jurídica». ${ }^{36}$

34 Así, «no es, pues, el caso de reducir a un solo y único derecho los múltiples derechos de la persona hasta hoy puestos en evidencia, sino a vincular o conectar esencialmente todos ellos con un fundamento único, lo que de hecho se produce en cuanto todos y cada uno de tales derechos se refieren siempre al yo" (Fernández Sessarego, Protección jurídica de la persona, Universidad de Lima, 1992, p.45).

35 Espinoza Espinoza, Aspetti attuali dei diritti delle persone nel codice civile peruviano, en La riforma del codice civile. Atti del XIII Congresso Nazionale dell'Associazione Italiana Giovani Avvocati, CEDAM, Padova, 1994, p.204.

36 Fernández Sessarego, op. cit., pp.37-38, quien afirma que: «no es técnicamente inadecuada la presencia de una pluralidad de derechos referidos a la protección de la persona humana siempre que, mediante cláusulas generales y abiertas, se permita al juez tutelar cualquier interés existencial no considerado como un derecho subjetivo típico por el ordenamiento jurídico positivo. Mediante este recurso de técnica jurídica, que comienza a incorporarse a ciertos ordenamientos jurídicos, se consigue superar la principal objeción sustentada contra el planteamiento ofrecido por la teoría pluralista. Es decir, el de su radical insuficiencia para lograr la protección integral y unitaria del ser humano.

No es contradictoria, sino más bien necesariamente complementaria, la contemporánea existencia de un fundamento único y general de tutela de la persona, como lo pretendería el monismo, y la presencia de una multiplicidad de derechos que, bajo un criterio técnico, constituyen sus indispensables especificaciones. La pluralidad de derechos de la persona insertos en el ordenamiento jurídico deberían interpretarse, en todo caso, como aplicaciones y desarrollos de una multiplicidad de intereses de la persona humana» (op. cit., p.47). 